\title{
Teacher's Gender-Related Beliefs about Mathematics ${ }^{1}$
}

\author{
ZHANG, Qiao-Ping* \\ Department of Curriculum and Instruction, Chinese University of Hong Kong, \\ Shatin, N. T., Hong Kong SAR; Email: qpzhang@ @ cuhk.edu.hk \\ WONG, Ngai-Ying \\ Department of Curriculum and Instruction, Chinese University of Hong Kong, \\ Shatin, N. T., Hong Kong SAR; Email: nywong@cuhk.edu.hk

\section{LAM, Chi-Chung} \\ Department of Curriculum and Instruction, Chinese University of Hong Kong, \\ Shatin, N. T., Hong Kong SAR; Email: chichunglam@cuhk.edu.hk
}

(Received March 15, 2013; Revised September 15, 2013; Accepted September 30, 2013)

Mathematics has been stereotyped as a male-dominated subject, and there is considerable evidence to support this belief. There has been much research in the past three decades on gender-related differences in elementary and secondary school mathematics. The research found that teachers possess different beliefs about male and female students that influence their teaching behaviour, which then directly or indirectly impact their students' behaviours, beliefs, and achievements in mathematics. Based on data collected from teacher questionnaire surveys in the Chinese Mainland and Hong Kong, this study examines teachers' beliefs about the achievements of boys and girls in mathematics. The study also compares the findings in the two regions surveyed. Results showed that teachers gave more attention to boys than girls, regardless of the teacher's gender. Not only are teachers more likely to recall more boys than girls, but also more boys than girls with average academic standards.

Keywords: gender difference, teachers' beliefs about mathematics; teacher-students interaction

MESC Classification: B50

MSC2010 Classification: 97B50

\footnotetext{
1 The earlier version has been presented at the 36th Conference of the International Group for the Psychology of Mathematics Education as a short oral presentation.

* Corresponding author
} 


\section{INTRODUCTION}

'For the most part we do not see and then define; we define first and then see. In the great blooming buzzing confusion of the outer world we pick out what our culture has already defined for us and we tend to receive that which we have picked out in the form stereotyped for us by our culture.'

(Walter Lippmann, 1922, p. 81)

International comparisons in mathematics achievement, such as the Programme for International Student Assessment (PISA) and the Trends in International Mathematics and Science Study (TIMMS), have often had a focus on gender differences in mathematics. Since the early 1970s, studies on the relationship between gender and mathematics education showed that there used to be clear gender differences favouring males in large-scale mathematics performance tests (Hyde, Fennema \& Lamon, 1990). Even though the number of girls entering mathematics increased, it remained a male domain. What does "Mathematics is a male domain" mean? This phrase came from Fennema \& Sherman (1976)'s most frequently used instruments: Fennema-Sherman Mathematics Attitudes Scales. It comprises nine different scales measuring attitudes related to various aspects of mathematics and mathematics learning: self-confidence, parents' and teachers' perceptions, effects of motivation, success, anxiety, usefulness and Mathematics as a male domain (the MD scale). The MD scale measures the extent to which mathematics is stereotyped as being masculine. The items in the MD instrument are formulated as statements such as 'Females are as good as males in geometry' and 'Girls who enjoy studying mathematics are a bit peculiar'. The responses are given in five grades ranging from strong agreement to strong disagreement. Further, using MD, Fennema \& Sherman (1977) found "Male responses differed significantly from female responses. While boys did not stereotype mathematics strongly as a male domain on this scale, they always stereotyped it more strongly than did females (p. 68)”. Brandell \& Staberg (2008) reported evidence that a view of mathematics as a male domain existed among upper secondary school in Sweden. The results showed that positive motivational beliefs such as mathematics being joyful and a subject you will need for the future are considered male. They further pointed out that there were two main lines of arguments can be identified as reasons for the male dominance in mathematics. The first line of argument refers to gender differences in performance and/or aptitude for mathematics: boys have performed better than girls and women have not been seen as suited for mathematics studies. The other line of argument is related to attitudes, school experiences, sex roles and the construction of gender identity and/or the gendered nature of mathematics itself (Brandell \& Staberg, 2008). 
A meta-analysis examining gender differences on attitudinal and affective variables associated with models explaining gender differences in mathematics learning was reported by Hyde, Fennema, Ryan, Frost \& Hopp (1990). The results indicated that when gender differences were noted, females tended to hold less functional beliefs about themselves as learners of mathematics and more negative attitudes toward mathematics than did males. Hyde et al. (1990) concluded that "gender differences in stereotyping math as a male domain have declined somewhat in the 1980s, but are still large" (p. 31). However, recent research has shown that these overall gender differences have narrowed in most countries (Mullis et al., 2000; OECD, 2001), and in some cases, boys are losing their advantage. Compared with PISA 2000, PISA 2003 showed the first incident of female advantage (OECD, 2001, 2004). In recent studies, this trend has persisted (Mullis et al., 2008). From above analysis, we could see gender difference is still an important issue in mathematics education.

Various attempts have been made to explain such gender differences (Leder, 1992; Leder, Forgasz, \& Solar, 1996), using biological, school, teacher, and parent variables (Leder, 1992). Researchers began to turn their attention from mathematics achievement in terms of conventional tests to other aspects. Some studies focused on affective factors, some on problem-solving heuristics (Cai, 2002), while others began to look at teacher influence (Beilock, Gunderson, Ramirez \& Levine, 2010; Leder, 1992; Tiedemann, 2002). This research on other aspects concluded that although gender differences in mathematics achievement might be narrowing, subtle differences persist. For instance, Horne (2004) found that although boys and girls seem to be equally engaged in group activities in the mathematics classroom, the nature of the engagement differs across the genders. There seems to be a 'glass ceiling' hindering women's further achievement in mathematics (Lee, 2002).

It is beliefs that count. Beliefs can be thought to form one part of an individual's metacognition, and they are "individual's judgment of the truth or falsity of a proposition, a judgment that can only be inferred from a collective understanding of what human beings say, intend, and do" (Pajares, 1992, p. 316), which could play an important role in student learning (Leder, Pehkonen \& Törner, 2002; Pehkonen, 1998; Philipp, 2007). Research has shown that the beliefs of teachers about gender roles have contributed to the process of social shaping that has resulted in the view that mathematics is a male domain (Fogasz, Leder \& Kloosterman, 2004; Hyde, Fennema \& Lamon, 1990; Hyde, Lindberg, Linn, Ellis \& Williams, 2008). In particular, teachers' beliefs about mathematics and mathematics teaching could shape the students' lived space (Wong, Marton, Wong \& Lam, 2002), which in turn will affect their learning outcomes. For instance, teachers' narrow conception of mathematics and their conservative view of effective mathematics teaching would lead them to create a restricted lived space for their students. This is supported by a num- 
ber of studies among the Chinese, both in Hong Kong and the Chinese Mainland (Wong, Wong, Lam \& Zhang, 2009).

Aligned with this thinking, we are curious to know if teachers' beliefs about gender differences in mathematics have influenced student learning. Teachers' beliefs and behaviors were related to gender may lead to deeper understanding of gender differences in mathematics as we perceive more about the mental life of teachers and students, and how this influences daily decisions about learning mathematics (Fennema, 1990). Research has repeatedly shown that girls lack confidence in mathematics. This is in accordance with their teachers' beliefs that female students lack self-confidence (Li, 1999; Soro, 2002). Mathematics teachers tend to believe that their male students have hidden talent, but underperform because they are lazy and careless, while female students tend to perform well due to diligence and hard work, even if they are not very talented. It is assumed that these gender-related beliefs of the teachers lead to different feedback being given to male and female students, thus contributing to the observed gender differences in the selfefficacy of students. Tiedemann (2002) analyzed the effect of teachers' gender stereotypes on their impressions of their students' competence and effort in mathematics. He reported that teacher perceptions were consistent with stereotypes of gender differences. This bias in teacher perceptions of their students' resources in mathematics is related to teacher's gender role stereotypic beliefs regarding the general distribution of mathematics talent between boys and girls.

The teachers' beliefs are also seen in their attention in the classroom. An earlier study revealed that boys received more attention in the mathematics classroom, received more challenging problems, and were situated in a more competitive environment than girls (Leder, 1990). Kelly (1988) found that although boys received more criticism than girls (44\% vs. $35 \%$ ) from teachers, they also received more praise (56\% vs. $48 \%$ ), while in Comfort (1996)'s findings, girls received more positive feedback from their teachers than boys. The observed gender differences may be, in part, attributed to the typical interaction patterns of teachers with male and female students (Fennema \& Peterson, 1986). In their meta-analysis study, Jones \& Dindia (2004) examined patterns of gender differences in teacher-initiated teacher-student interactions and found that teachers initiated more overall interactions and more negative interactions, but not more positive interactions, with male students than with female students. However, Younger, Warrington \& Williams (1999) found that more girls than boys took the opportunity to initiate questions, sought clarification on work-related matters, and made best use of the support of the teacher.

In Li (1999)'s model of teacher's beliefs and gender, he involved six critical categories to gender-related studies (see Figure 1). The model showed teacher behaviours were in large part caused by their beliefs and teacher behaviours, including teacher-student interaction, may stress or change their beliefs. Similarly, teacher beliefs affected student 
beliefs, their behaviours and, ultimately, their achievements.

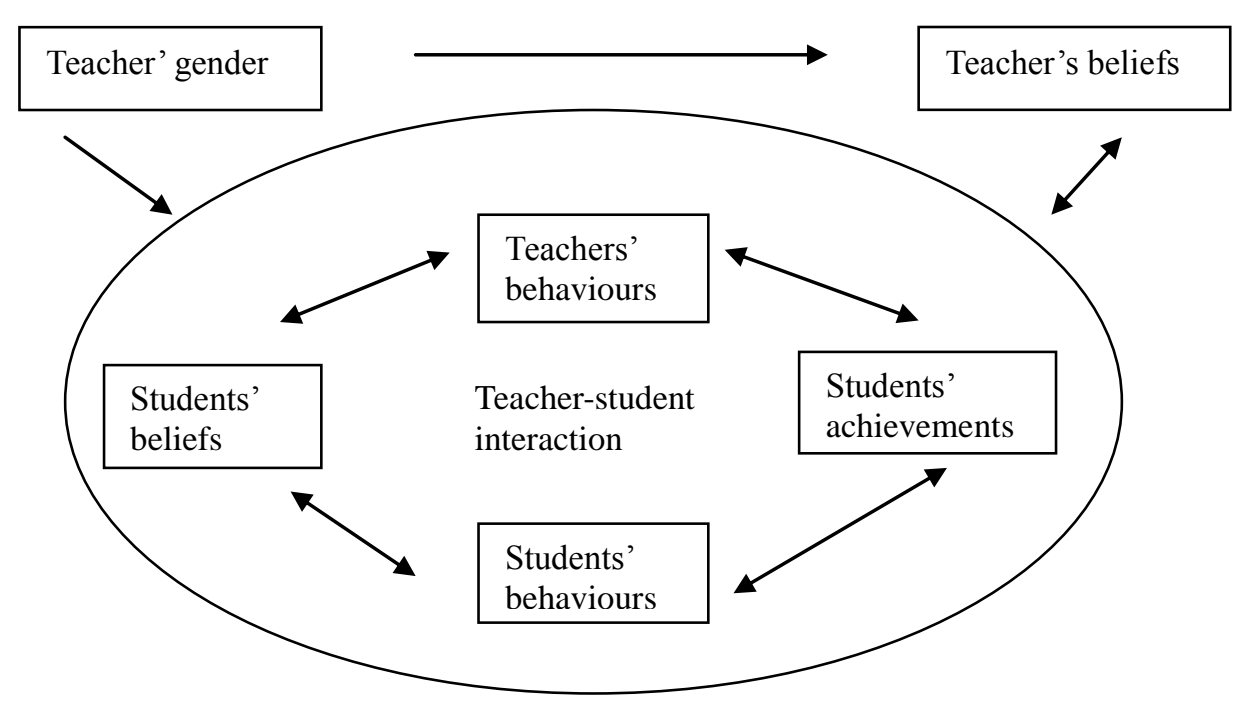

Figure 1. Model of Teacher's beliefs and gender difference

This idea is also similar with Ajezn (1991)'s theory of planned behavior, which has been empirical proven to the understanding and identifying beliefs-based factors influencing behaviour and intention. What an individual does is determined by personal motivation which is determined by attitude, social support and perceived behavioral control. If one can determine the elements that impact intention, then one can more accurately predict whether an individual will engage in a particular behavior (Ajezn, 1991).

In recent years, on the surface, gender differences in mathematics seem to be narrowing; however, there is a need to see if subtle differences still exist. On the one hand, those research findings mentioned above are mostly conducted in Western context. In the Chinese context, the empirical studies concerned with gender-related beliefs are not enough. On the other hand, the Chinese community has a particular interest in this issue, not only because the Chinese have excelled in mathematics (Wong, 2004), but also because the Chinese culture has long been perceived as male-dominated. Thus, the purpose of this study is to see whether boys still receive more attention (teacher-student interactions) from mathematics teachers (regardless of the teacher's gender), and whether there are still gender differences in teachers' beliefs about mathematics in the Chinese context? 


\section{METHODOLOGY}

\section{Respondents}

In the current study, 87 secondary mathematics teachers from the central Chinese city of Wuhan (47 males, 40 females) and 100 secondary teachers from Hong Kong (52 males, 48 females) were invited to participate. They are in-service mathematics primary or secondary teachers who attend teacher education programme at university.

\section{Questionnaire}

To investigate teacher's gender-related beliefs about mathematics, we designed a simple open-ended questionnaire to collect data. The procedure is:

A) The respondents were first asked to recall three students who immediately came to their minds.

B) They were then asked to write down the gender of the three students and indicate whether, according to their impression of students' academic performance, the students were 'good' or 'average'.

C) They were then asked to rate their level of agreement with four simple statements (agree, disagree, neutral):

1. Boys are much better in mathematics than girls.

2. Boys are more interested in mathematics than girls.

3. Boys are more confident in mathematics than girls.

4. Mathematics is a male subject.

D) Finally, the respondents were asked to indicate their own gender.

\section{RESULTS}

When we asked teachers to immediately recall three students, teachers from the Chinese Mainland recalled 170 boys and 91 girls. The Hong Kong teachers recalled 174 boys and 126 girls. Overall, regardless of gender, teachers were more likely to recall boys than girls in both regions (Figure 2). When we took the two regions as a whole, male teachers were more likely than female teachers to recall boys $(64.6 \%$ vs. $57.6 \%)$.

While, we know there are many reasons that a teacher tend to recall boys or girls, such as he/she maybe are more naughty or active. So the followed questions (B, C, D) are im- 
portant to reflect the teacher's gender-related beliefs. As for students' level of academic standard, both male and female teachers recalled more students with high standards than average standards. And even for average students, male teachers were more likely than female teachers to remember boys than girls (Figures $3 a$ and $3 b$ ).

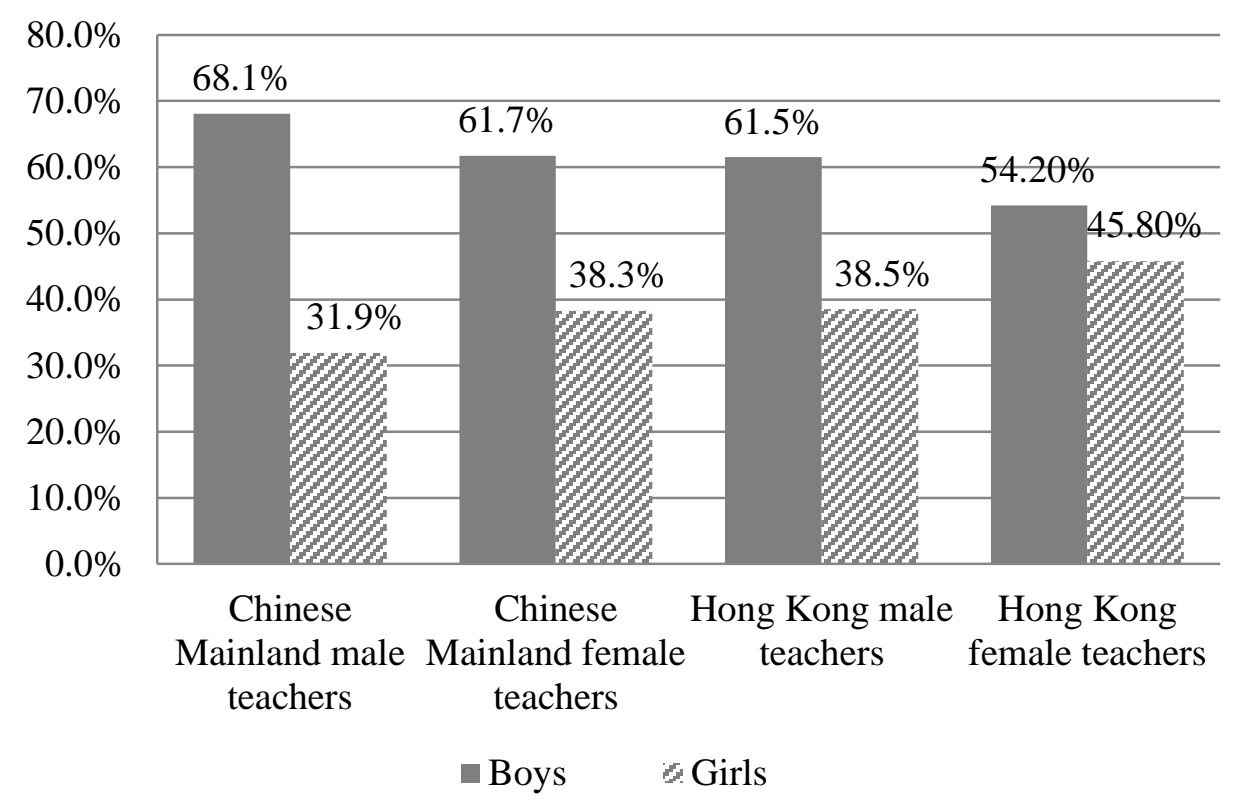

Figure 2. Students recalled by female teachers

- Boys \# Girls

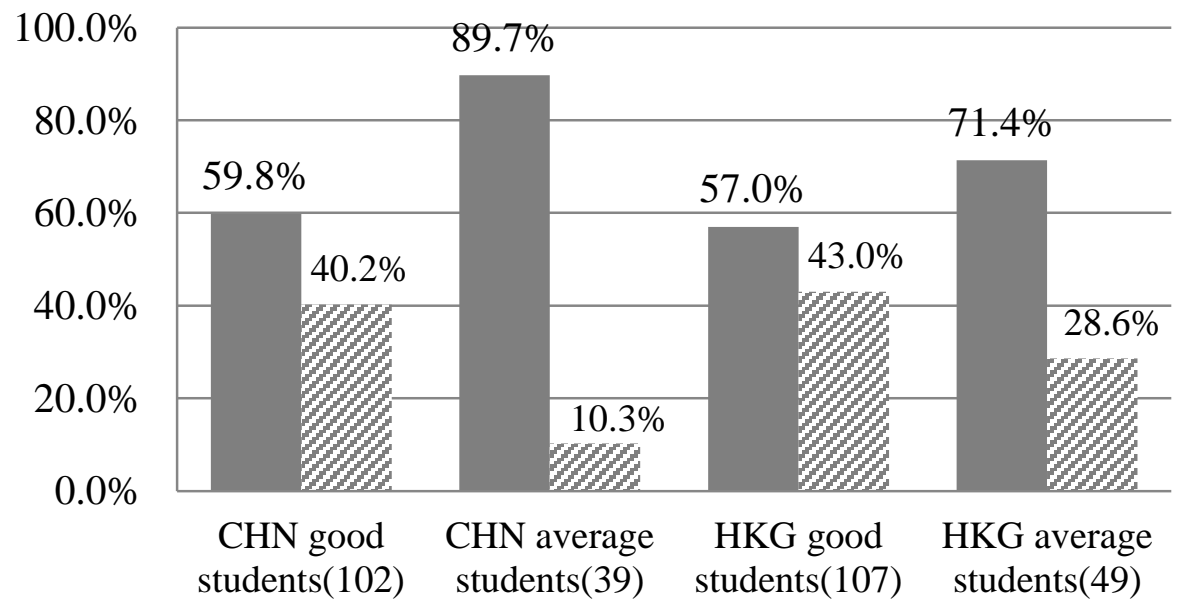

Figure 3a. Students recalled by male teachers by academic level and gender (CHN: Chinese Mainland, HKG: Hong Kong) 


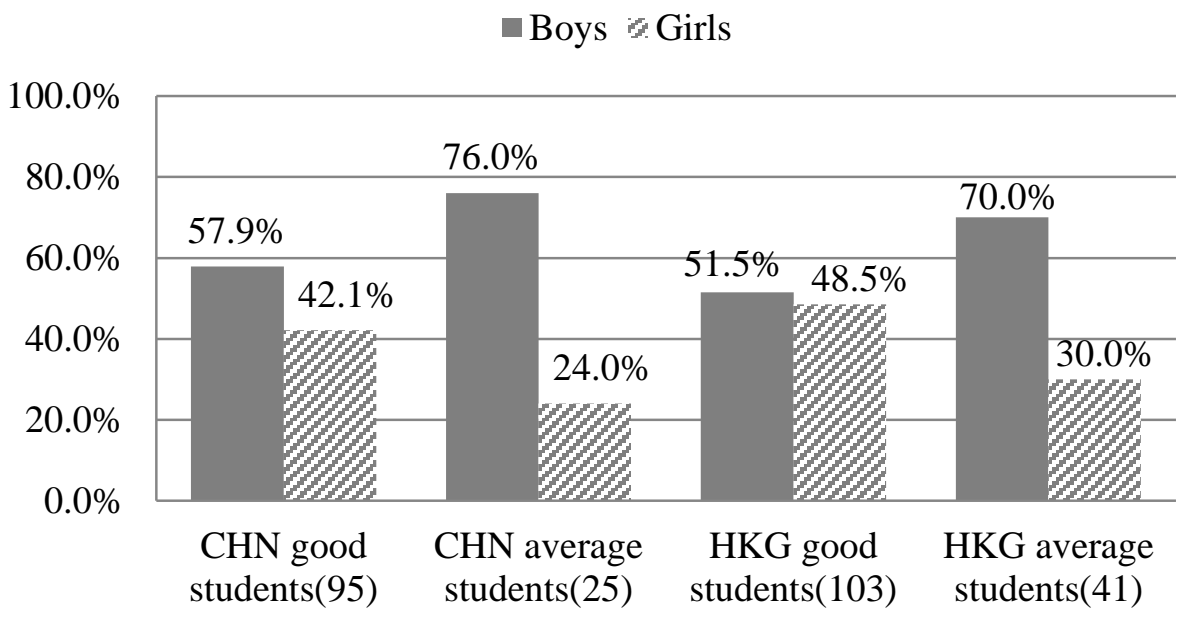

Figure 3b. Students recalled by female teachers by academic level and gender (CHN:

Chinese Mainland, HKG: Hong Kong)

With regard to the four statements to be rated, the results showed that the teachers in the two regions had much in common. A majority of teachers in both regions agreed with the first three statements. For the Chinese Mainland teachers $(n=87)$, the percentages agreeing to the first three statements were $58.6 \%, 64.4 \%$, and $70.1 \%$ respectively. For the Hong Kong teachers ( $\mathrm{n}=100)$, the percentages were $50.0 \%, 71.0 \%$, and $60.0 \%$ respectively.

When we compare the two regions, the percentages of teachers who agreed to the first and third statements were higher in the Chinese Mainland (58.6\% and 70.1\% respectively) than in Hong Kong (50.0\% and $60.0 \%$ respectively). For the second statement, the percentage of Hong Kong teachers who agreed (71.0\%) was higher than the percentage of Chinese Mainland teachers (64.4\%).

For the fourth statement-'Mathematics is a male subject' - the majority of teachers in the two regions chose 'neutral' or 'disagree': $86.0 \%$ of Hong Kong teachers, compared to $81.6 \%$ of Chinese Mainland teachers (Figures $4 \mathrm{a}$ and $4 \mathrm{~b}$ ). 


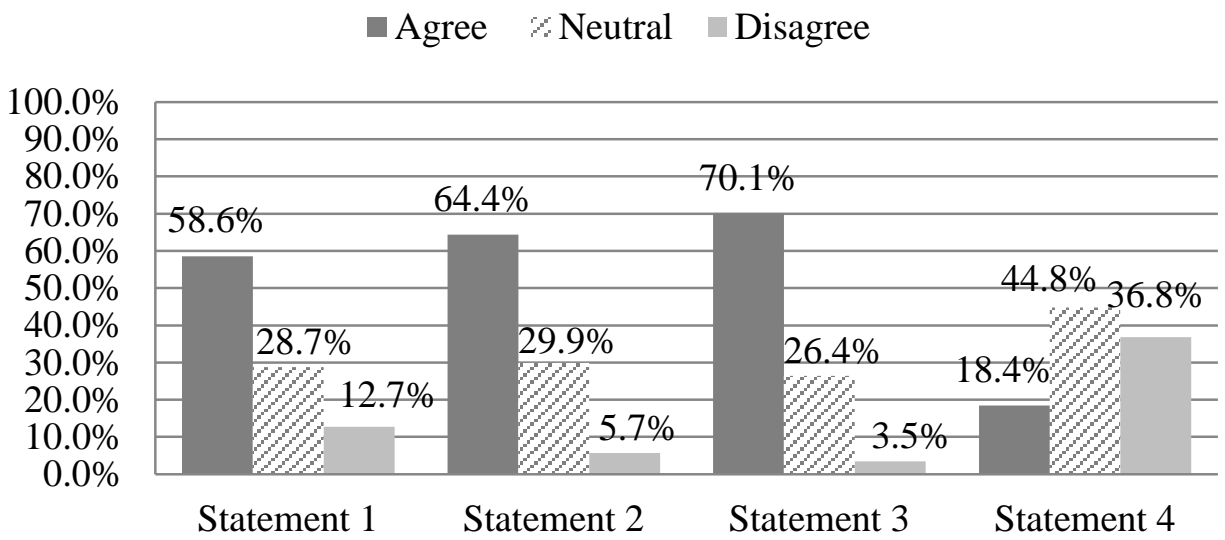

Figure 4a. Chinese Mainland teachers' beliefs on gender difference in mathematics

- Agree Neutral Disagree

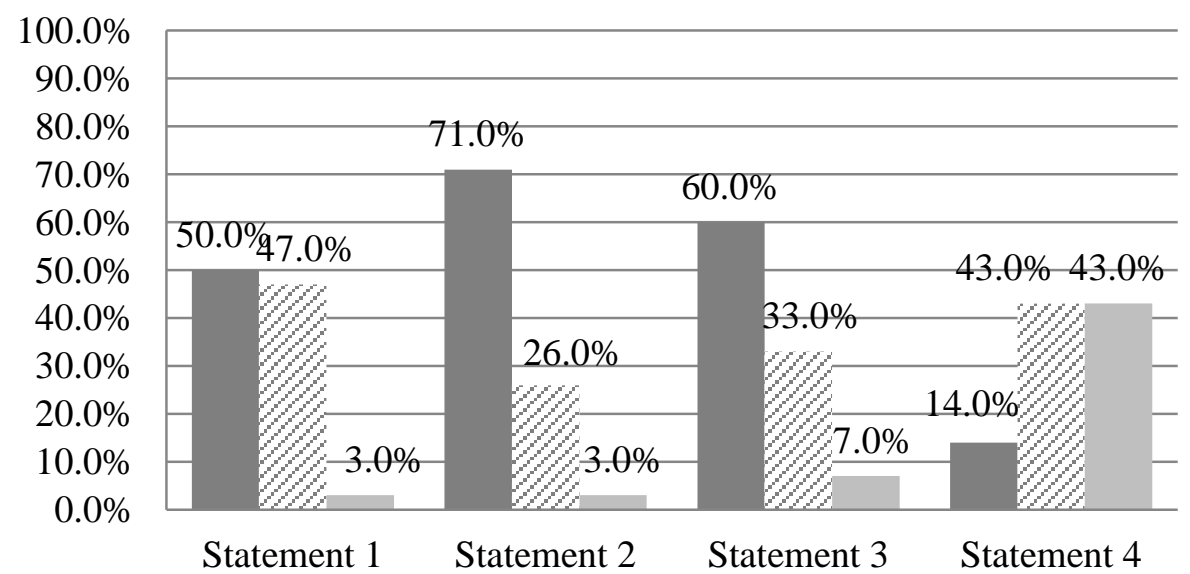

Figure 4b. Hong Kong teachers' beliefs on gender difference in mathematics

An independent sample t-test on teachers' gender-related beliefs about these four statements shows no significant difference between the four statements by the teachers in Hong Kong and in the Chinese Mainland. If we look at the gender of the teachers, for most of the statements, more male teachers agreed with the statements than female teachers. This gap was smaller in Hong Kong than in the Chinese Mainland. The only exception is the third statement ('Boys are more confident in mathematics than girls'); in this 
case, more female teachers than male teachers in Hong Kong agreed with this statement. Please refer to Figures $5 \mathrm{a}$ and $5 \mathrm{~b}$ for detail.

- Males \& Females

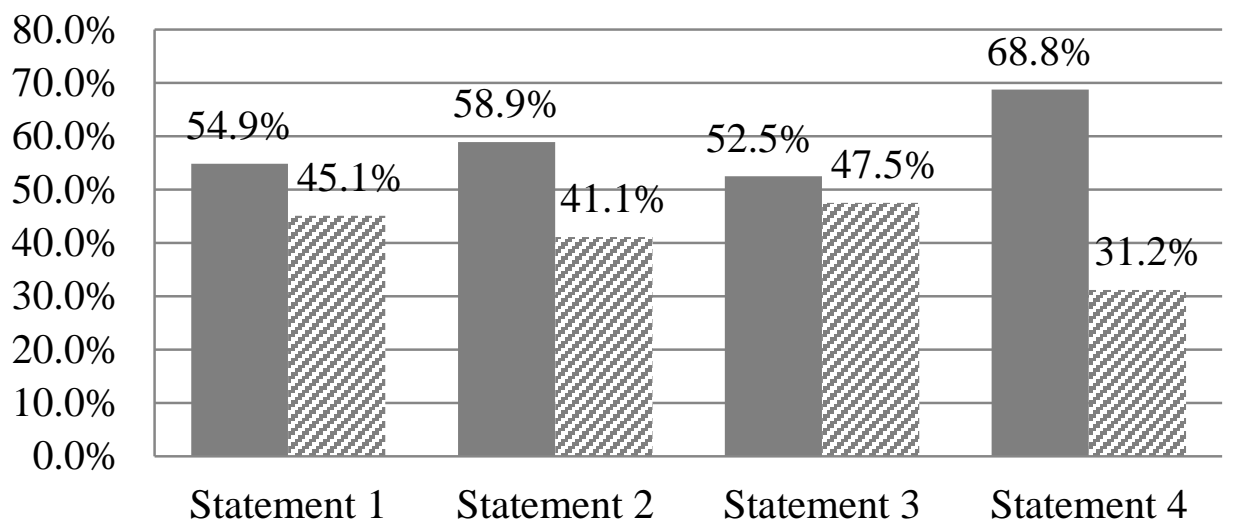

Figure 5a. Teachers' gender related beliefs about mathematics among teachers in the Chinese mainland

- Males z Females

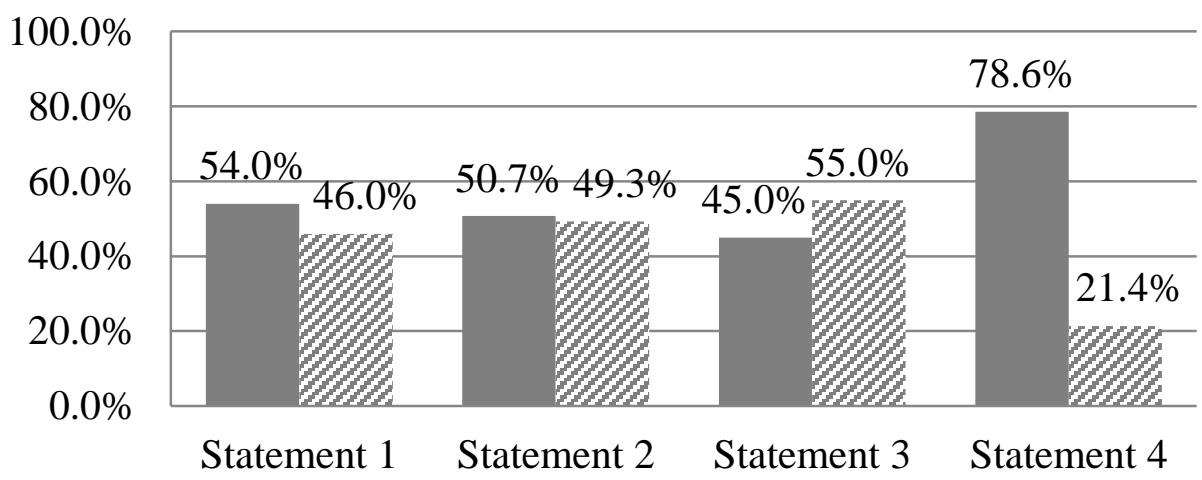

Figure 5b. Gender related beliefs about mathematics among teachers in Hong Kong

\section{DISCUSSION AND CONCLUSION}

The above findings reveal that the gender-biased beliefs of teachers about students' abilities in mathematics have persisted. In general, more attention is given to boys than girls, regardless of the teacher's gender. Not only are teachers more likely to recall more 
boys than girls with high academic standards, but also more boys than girls with average academic standards. These are consistent with previous findings that teachers gave more attentions on boys than girls (Kelly, 1988; Leder, 1990) and high-achieving students than low-achieving ones (Wilson, 1999). As reflected in the responses to the four statements, a majority of the teachers think that boys perform better and have more confidence in mathematics. However, they disagreed with the statement that mathematics is a male subject. Sometimes teachers are unaware and deny that they hold or perpetuate biased perceptions of males and females.

If the first statement- 'Boys are much better in mathematics than girls'-is an impression rather than fact (i.e., the boys did not actually outperform the girls), then the gender bias is even more subtle. In a sense, if such a bias really exists, teachers do not realise it. This bias is more prevalent among male teachers and among teachers from the Chinese Mainland. Inevitably, such beliefs are culturally dependent, as indicated in previous studies (see for example Else-Quest, Hyde \& Linn, 2010; Ma, 2010). These beliefs 'quietly' influence how teachers teach. In Furinghetti's (1997) term, they act as a 'ghost' and have a subtle influence on classroom teaching. When we look deeper into the differences in mathematics achievement between boys and girls, we can see that the beliefs of teachers do play a role in these gender-related differences (Li, 1999; Soro, 2002; Tiedemann, 2002).

Although only a small number of participants were involved in this study, the result is clear: there are subtle gender differences in beliefs on mathematics achievement, and these differences are worth serious attention. While open-ended questions were used in this study instead of Likert-type questionnaires, interviews and classroom observation could be used in future studies. This study is not the conclusive findings to explain why gender difference exists in mathematics education. We just proposed that teacher's gender-related beliefs, especially the teachers' attention or teacher-students interactions in the classroom could be an important explanatory factor when we consider the gender difference in students learning.

Through a comparison of different international tests, Ma (2010) found that gender differences in mathematics achievement on the PISA were significantly and negatively predicted by women's share of research positions and parliamentary seats, as well as by the male-to-female ratio in economic activity rates. When women participate at the rate of men in the labour market (particularly in science occupations) and in the national government, there is a smaller gender gap in mathematics achievement on the PISA. In nations where girls have more equal access to education, girls and boys tend to perform similarly on the TIMSS.

Back in the classroom, do our teachers provide equal learning opportunities to boys and girls? Echoed with Ajezn (1991)'s theory and Li (1999)'s model, the findings might 
remind our teachers should learn to recognize and eliminate gender bias in their interactions with students both within and outside the classroom. They also should be aware of their gender-biased behavior/practices and promote gender equity in their classrooms.

\section{REFERENCES}

Ajzen, I. (1991). The theory of planned behaviour. Organizational Behavior and Human Decision Processes 50(2), 179-211.

Beilock, S. L.; Gunderson, E. A.; Ramirez, G. \& Levine, S. C. (2010). Female teachers' math anxiety affects girls' math achievement. Proc. Natl Acad. Sci. USA 107(5), 1060-1063. ME 2011b.00203

Brandell, G. \& Staberg, E. M. (2008). Mathematics: a female, male or gender neutral domain? A study of attitudes among students at secondary level. Gender and Education, 20(5), 495-509.

Cai, J. (2002). Exploring gender differences of U.S. and Chinese students in their solution processes of solving routine and nonroutine mathematical problems. Research in Middle Level Education 26(1), 1-23.

Comfort, O. (1996). Gender-related differences in classroom interaction. Journal of Instructional Psychology 23(4), 275-286.

Else-Quest, N. M., Hyde, J. S., \& Linn, M. C. (2010). Cross-national patterns of gender differences in mathematics: A meta-analysis. Psychological Bulletin, 136, 103-127.

Fennema, E. (1990). Teachers' beliefs and gender differences in mathematics. In: E. Fennema \& G. C. Leder (Eds). Mathematics and gender (pp. 169-87). New York, U.S.A: Teachers' College Press. ME 1991b.02905

Fennema, E. \& Peterson, P. L. (1986). Teacher-student interactions and sex-related differences in learning mathematics. Teach. Teach. Educ. 2(1), 19-42. ME 1987x.00191

Fennema, E. \& Sherman, J. (1976). Fennema-Sherman Mathematics Attitude Scales: Instruments designed to measure attitudes toward the learning of mathematics by females and males. Journal for Research in Mathematics Education 7(5), 324-326. ERIC EJ148896

(1977). Sex-related differences in mathematics achievement, spatial visualization and affective factors. American Educational Research Journal 14(1), 51-71.

Forgasz, H. J.; Leder, G. C. \& Kloosterman, P. (2004). New perspectives on the gender stereotyping of mathematics. Math. Think. Learn. 6(4), 389-420. $\quad$ ME 2005a.00100

Furinghetti, F. (1997). On teachers' conceptions: From a theoretical framework to school practice. In: G. A. Makrides (Ed.). Proceedings of the first mediterranean conference on mathematics MC-MEA'97(pp. 277-287). Cyprus: Cyprus Pedagogical Institute and Cyprus Mathematical Society. ME 1999f.03760 
Horne, M. (2004). Early gender differences. In: M. J. Høines \& A. B. Fuglestad (Eds.), Proceedings of the 28th Conference of the International Group for the Psychology of Mathematics Education (Volume 3, pp. 65-72). Bergen, Norway: Bergen University College. http://www.emis.de/proceedings/PME28/RR/RR160_Horne.pdf

Hyde, J. S.; Fennema, E. \& Lamon, S. (1990). Gender differences in mathematics performance: A meta-analysis. Psychological Bulletin 107(2), 139-155.

Hyde, J. S.; Fennema, E.; Ryan, M.; Frost, L. A. \& Hopp, C. (1990). Gender comparisons of mathematics attitudes and affect, a meta-analysis. Psychology of Women Quarterly 14(3), 299-324.

Hyde, J. S.; Lindberg, S. M.; Linn, M. C.; Ellis, A. \& Williams, C. (2008). Gender similarities characterize math performance. Science 321, 494-495.

Jones, S. M. \& Dindia, K. (2004). A meta-Analytic perspective on sex equity in the classroom. Review of Educational Research 74 (4), 443-471

Kelly, A. (1988). Gender differences in teacher-pupil interaction: A meta-analytic review. Research in Education 39, 1-23.

Leder, G. C. (1990). Teacher-student interactions, mathematics and gender. In: E. Fennema \& G. C. Leder (Eds.), Mathematics and gender (pp. 149-168). New York, U.S.A.: Teacher's College Press. ME 1991d.02905

(1992). Mathematics and gender: Changing perspectives. In: D. A. Grouws (Ed.), Handbook of research on mathematics teaching and learning (pp. 597-622). New York, U.S.A.: Macmillan. ME 1993f.01809

Leder, G. C.; Forgasz, H. J. \& Solar, C. (1996). Research and intervention programs in mathematics education: A gendered issue. In: A. Bishop, K. Clements, C. Keitel, J. Kilpatrick \& C. Laborde (Eds.), International handbook of mathematics education (Vol. 4, Pt. 2, pp. 945-985). Dordrecht, Netherlands: Kluwer. ME 1998f.03924

Leder, G. C.; Pehkonen, E. \& Törner, G. (Eds.) (2002). Beliefs: A hidden variable in mathematics education? Dordrecht, Netherlands: Kluwer. ME 2003c.01993

Lee, S. M. (2002). Do Asian American faculty face a glass ceiling? American Educational Research Journal 39(3), 695-724.

Li, Q. (1999). Teachers' beliefs and gender differences in mathematics: A review. Educational Research, 41(1), 63-76.

Lippmann, W. (1922). Public opinion. New York, U.S.A.: Harcourt, Brace and Company.

Ma, X. (2010). Gender differences in mathematics achievement: Evidence from latest regional and international student assessments. In H. J. Forgasz, J. R. Becker, K. Lee, \& O. Steinthorsdottir (Eds.), International perspectives on gender and mathematics education (pp. 225-248). Charlotte, NC, U.S.A.: Information Age Publishing.

Mullis, I. V. S.; Martin, M. O.; Foy, P., Olson, J. F.; Preuschoff, C.; Erberber, E.; Arora, A. \& Galia, J. (2008). TIMSS 2007 International Mathematics Report: Findings from IEA's Trends 
in International Mathematics and Science Study at the Fourth and Eighth Grades. Chestnut Hill, MA, U.S.A.: TIMSS \& PIRLS International Study Center, Boston College.

Mullis, I. V. S.; Martin, M. O.; Gonzalez, E. J.; Gregory, K. D.; Garden, R. A.; O’Connor, K. M.;

Chrostowski, S. J. \& Smith, T. A. (2000). TIMSS 1999 international mathematics report: Findings from IEA's Repeat of the Third International Mathematics and Science Study at the eighth grade. Chestnut Hill, MA: TIMSS \& PIRLS International Study Center, Boston College. Organization for Economic Cooperation and Development (OECD). (2001). Knowledge and skills for life: First results from PISA 2000. Paris, France: OECD Publishing.

(2004). Learning for tomorrow's world: First results from PISA 2003. Paris, France: OECD Publishing.

Pajares, M. F. (1992). Teachers beliefs and educational research: Cleaning up a messy construct. Review of Educational Research, 62(3), 307-332.

Pehkonen, E. (1998). On the concept "mathematical belief”. In. E. Pohkonen \& G.. Törner (Eds.). The State-of-Art in Mathematics-Related Belief Research: Results of the MAVI activities - Research Report 195 (pp. 11-36). Helsinki, Finland: Department of Teacher Education, University of Helsinki.

Philipp, R. A. (2007). Mathematics teachers' beliefs and affect. In F. K. Lester (Ed.), Second handbook of research on mathematics teaching and learning (pp. 257-315). Charlotte, U.S.A.: Information Age.

Soro, R. (2002). Teachers' beliefs about gender differences in mathematics: 'girls or boys?' scale. In A. D. Cockburn, \& E. Nardi (Eds.), Proceedings of the $26^{\text {th }}$ conference of the International Group for the Psychology of Mathematics Education, volume 4 (pp. 225-232). Norwich, UK: University of East Anglia.

Tiedemann, J. (2002). Teachers' Gender Stereotypes as Determinants of Teacher Perceptions in Elementary School Mathematics. Educational Studies in Mathematics, 50(1), 49-62.

Younger, M., Warrington, M., \& Williams, J. (1999) .The gender gap and classroom interactions: reality and rhetoric. British Journal of Sociology of Education, 20, 325-341.

Willson, J. (1999). High and low achievers' classroom interaction patterns in an upper primary classroom. Paper presented at the AARE Conference, Melbourne, Australia, 29 November-2 December 1999.

Wong, N. Y., Marton, F., Wong, K. M., \& Lam, C. C. (2002). The lived space of mathematics learning. Journal of Mathematical Behavior, 21, 25-47.

Wong, N. Y. (2004). The CHC learner's phenomenon: Its implications on mathematics education. In L. Fan, N. Y. Wong, J. Cai, \& S. Li (Eds.), How Chinese learn mathematics: Perspectives from insiders (pp. 503-534). Singapore: World Scientific.

Wong, Q. T., Wong, N. Y., Lam, C. C., \& Zhang, Q. P. (2009). Beliefs about mathematics and effective teaching among elementary mathematics teachers in Hong Kong. In: J. Cai, G. Kaiser, 
B. Perry \& N. Y. Wong (Eds.), Effective mathematics teaching from teachers' perspectives: National and cross-national studies (pp. 217-234). Rotterdam, Netherlands: Sense Publishers. 